\section{Cahiers de Narratologie}

Analyse et théorie narratives

$25 \mid 2013$

Humour et modernité dans les littératures de langues romanes du XIXe au XXIe siècle

\title{
Esthétique du rire
}

\section{Cinzia Falabella}

\section{(2) OpenEdition}

Journals

\section{Édition électronique}

URL : http://journals.openedition.org/narratologie/6793

DOI : 10.4000/narratologie.6793

ISSN : 1765-307X

Éditeur

LIRCES

\section{Référence électronique}

Cinzia Falabella, «Esthétique du rire », Cahiers de Narratologie [En ligne], 25 | 2013, mis en ligne le 20 décembre 2013, consulté le 22 septembre 2020. URL : http://journals.openedition.org/narratologie/ 6793 ; DOI : https://doi.org/10.4000/narratologie.6793

Ce document a été généré automatiquement le 22 septembre 2020

Article L.111-1 du Code de la propriété intellectuelle. 


\title{
Esthétique du rire
}

\author{
Cinzia Falabella
}

\section{RÉFÉRENCE}

Esthétique du rire, sous la direction d'Alain Vaillant, Paris, Presses Universitaires de Paris Ouest, 2012, $408 \mathrm{p}$.

\section{NOTE DE L'ÉDITEUR}

Cinzia Falabella est doctorante au LIRCES, Université Nice Sophia Antipolis (directeur : Edwige Comoy Fusaro)

1 Rire et faire rire constitue désormais une pratique culturelle à part entière qui a envahi les théâtres, les cinémas et les médias. On ne compte plus les essais philosophiques, les colloques universitaires et les débats médiatiques sur l'art du rire. Si l'ouvrage dirigé par Alain Vaillant (professeur de littérature française à l'université Paris Ouest Nanterre La Défense et spécialiste reconnu de la question), Esthétique du rire, semble participer de ce regain d'intérêt pour le rire, il se caractérise néanmoins par une approche méthodologique bien particulière et tout à fait originale. Tout d'abord, comme Alain Vaillant l'affirme dans son introduction, il rejette la division traditionnelle en genres (l'ironie, la parodie, le comique, etc.) pour revendiquer l'unité du rire. En conséquence, si le rire est présenté comme un mécanisme psychique propre à l'être humain, il ne doit viser qu'à faire rire sans se soumettre à l'élucidation d'enjeux philosophiques ou idéologiques. Pour appuyer sa théorie, Alain Vaillant cite l'essai De l'essence du rire de Charles Baudelaire (p. 11), où la définition du «comique absolu » (par opposition au "comique significatif », qui a le défaut de pervertir le rire) rejoint celle proposée dans son ouvrage: une esthétique qui utilise la technique de l'humour dans le seul but de susciter le pur plaisir de la jubilation.

2 Afin de saisir le rire dans son unité et de le reconnaître comme une manifestation culturelle inscrite dans le temps, Alain Vaillant a réuni les interventions de treize 
spécialistes qui abordent ce sujet dans une perspective diachronique, s'intéressant principalement aux changements progressifs de ce phénomène du Moyen Âge jusqu'à nos jours. Les principaux nœuds théoriques de cette démarche ont donné vie, tout naturellement, aux quatre parties de cet ouvrage. La première ( La Renaissance du rire ») est consacrée au Moyen Âge et à la Renaissance. Au Moyen Âge, on réprime l'humour en raison de son lien avec le corps mais, pendant la Renaissance, on assiste à la libération du rire reconnu comme étant le propre de l'homme. La deuxième partie ("Les ruses du rire classique ») illustre comment, à la période classique, le rire devient une qualité propre au monde aristocratique conçu comme un monde clos sur luimême: l'art de faire de l'esprit, les jeux jubilatoires ou le badinage mondain se conforment toujours à des règles sociales bien déterminées. Après la période révolutionnaire, qui marque une rupture avec cette extraordinaire sophistication pour laisser la place à un humour violent et iconoclaste, on assiste à l'éclosion du rire moderne, phénomène décrit dans la troisième partie de l'ouvrage («L'invention du rire moderne »). Avec le déclin du pouvoir monarchique et de la religion, deux autorités qui sont, depuis toujours, soumises à une contestation permanente, les auteurs s'attèlent, par le rire, à la revendication de la dimension ludique de la littérature et à la revalorisation des textes mineurs. Le rire devient un jeu d'images où la réalité est déformée par des représentations fantasmatiques et grotesques, et, dans ce contexte, certaines formes d'art, comme la caricature, y prennent une place de choix. Mais c'est surtout au vingtième siècle que le rire se transforme véritablement en "rire démocratique " (quatrième et dernière partie), bénéficiant du formidable essor des nouveaux médias. L'effet de masse produit par ces nouveaux médias garantit une reconnaissance de l'humour qui s'élève au statut d'art poétique.

Cependant, comme l'affirme Alain Vaillant dans son introduction, il ne faut pas que cet excursus historique nous éloigne de l'essentiel : « la nature anthropologique du rire » (p. 16). Au-delà de toutes successions chronologiques et de toutes classifications, cet essai collectif veut démontrer que le rire n'est rien d'autre qu'un phénomène qui jaillit de l'inconscient de l'être humain. Et c'est bel et bien cette composante irrationnelle et incontrôlable qui, lorsqu'elle se déclenche, transforme l'humour en phénomène d'ordre esthétique. L'originalité de l'ouvrage dirigé par Alain Vaillant consiste donc à souligner cet aspect mystérieux et presque troublant de l'humour. 